\title{
Constriction band syndrome occurring in the setting of in vitro fertilization and advanced maternal age
}

\author{
Brian Rinker MD, Henry C Vasconez MD
}

B Rinker, HC Vasconez. Constriction band syndrome occurring in the setting of in vitro fertilization and advanced maternal age. Can J Plast Surg 2006;14(1):41-44.

The debate as to the pathogenesis of constriction band syndrome began with Hippocrates and continues today. The exogenous theory attributes the condition to entanglement of the fetus in the amniotic remnants following premature rupture of the amnion, which is in contrast to the endogenous, or genetic, mechanism.

A case of constriction band syndrome in the setting of in vitro fertilization, where the child was genetically unrelated to the birth mother, is presented. Constriction band syndrome has been reported following amniocentesis and chorionic villus sampling, but it has not heretofore been presented in the setting of in vitro fertilization. In addition, the present case presents an opportunity to separate maternal from genetic factors and, possibly, shed some light on the etiology of the condition.

Key Words: Amniotic band; Congenital; Constriction band; In vitro fertilization

\section{Maladie des brides amniotiques dans le contexte d'une fécondation in vitro chez une femme d'un âge assez avancé}

Le débat sur la pathogenèse de la maladie des brides amniotiques a commencé avec Hippocrate et se poursuit encore aujourd'hui. D'après la théorie des facteurs exogènes, la maladie s'explique par l'enchevêtrement du fœetus dans les débris du sac amniotique à la suite de la rupture prématurée de l'amnios, théorie qui s'oppose au mécanisme endogène, ou génétique.

Voici un cas de maladie des brides amniotiques dans le contexte d'une fécondation in vitro, dans lequel le fœtus n'avait aucun lien génétique avec la mère qui lui a donné naissance. La malformation a déjà été associée, dans des rapports, à l'amniocentèse et à la biopsie de villosités choriales, mais elle n’a jamais été présentée jusqu'à maintenant dans le contexte de la fécondation in vitro. De plus, le cas permet de distinguer les facteurs maternels des facteurs génétiques et de mieux comprendre l'étiologie de la maladie.
$\mathrm{C}$ onstriction band syndrome is characterized by the presence of circumferential indentations of the limbs or digits at birth, and it is often associated with distal edema, intrauterine amputations or syndactyly. The condition occurs sporadically, and its prevalence is 7.7 in 10,000 live births (1).

The etiology of constriction band syndrome is unknown but has been the subject of debate since the time of Hippocrates (2). The exogenous theory, proposed by Torpin (2) and Kino (3), attributes the condition to the entanglement of the fetus in the amniotic remnants (bands) following premature rupture of the amnion. This is in contrast to the endogenous theory suggested by Streeter (4), which ascribes the condition to a focal developmental error affecting the subcutaneous germ cell layer. More recent experimental work by Lockwood et al $(5,6)$ has yielded evidence for a vascular endothelial injury as the primary endogenous mechanism.

Little is known about the risk factors for constriction band syndrome, but maternal age has been shown to affect risk in an inverse fashion $(7,8)$. In addition, there have been reports associating amniotic band syndrome with maternal trauma, oophorectomy during pregnancy (9), intrauterine contraceptive device (10), amniocentesis (11-15) and chorionic villus sampling (16).
The purpose of the present paper was to present a recent case of constriction band syndrome occurring in the setting of in vitro fertilization (IVF) and advanced maternal age.

\section{CASE PRESENTATION}

The patient was a white male born at full-term gestation, weighing $3.04 \mathrm{~kg}$. The patient's mother was 47 years of age, G3P2, and her pregnancy was the result of IVF and embryonic implantation. The embryo was the product of her husband's sperm and a donated ovum. The egg donor was a healthy, nulliparous, white woman in her early 20s. The pregnancy was complicated by hypertension and abruptio placentae. The labour was induced at 39 weeks, and the delivery was complicated by fetal intolerance of labour, prompting an emergent cesarian section. At birth, the infant was noted to have a lipomyelomeningocele, as well as constriction bands affecting both hands. Apgar scores at $1 \mathrm{~min}$ and $5 \mathrm{~min}$ were 8 and 9, respectively. The child was transferred to the neonatal intensive care unit where ventilator support was required for two days.

The left hand configuration consisted of acrosyndactyly involving the thumb, index and long fingers. The thumb and index fingers appeared foreshortened. The right hand was found to have acrosyndactyly involving the thumb, long, ring 

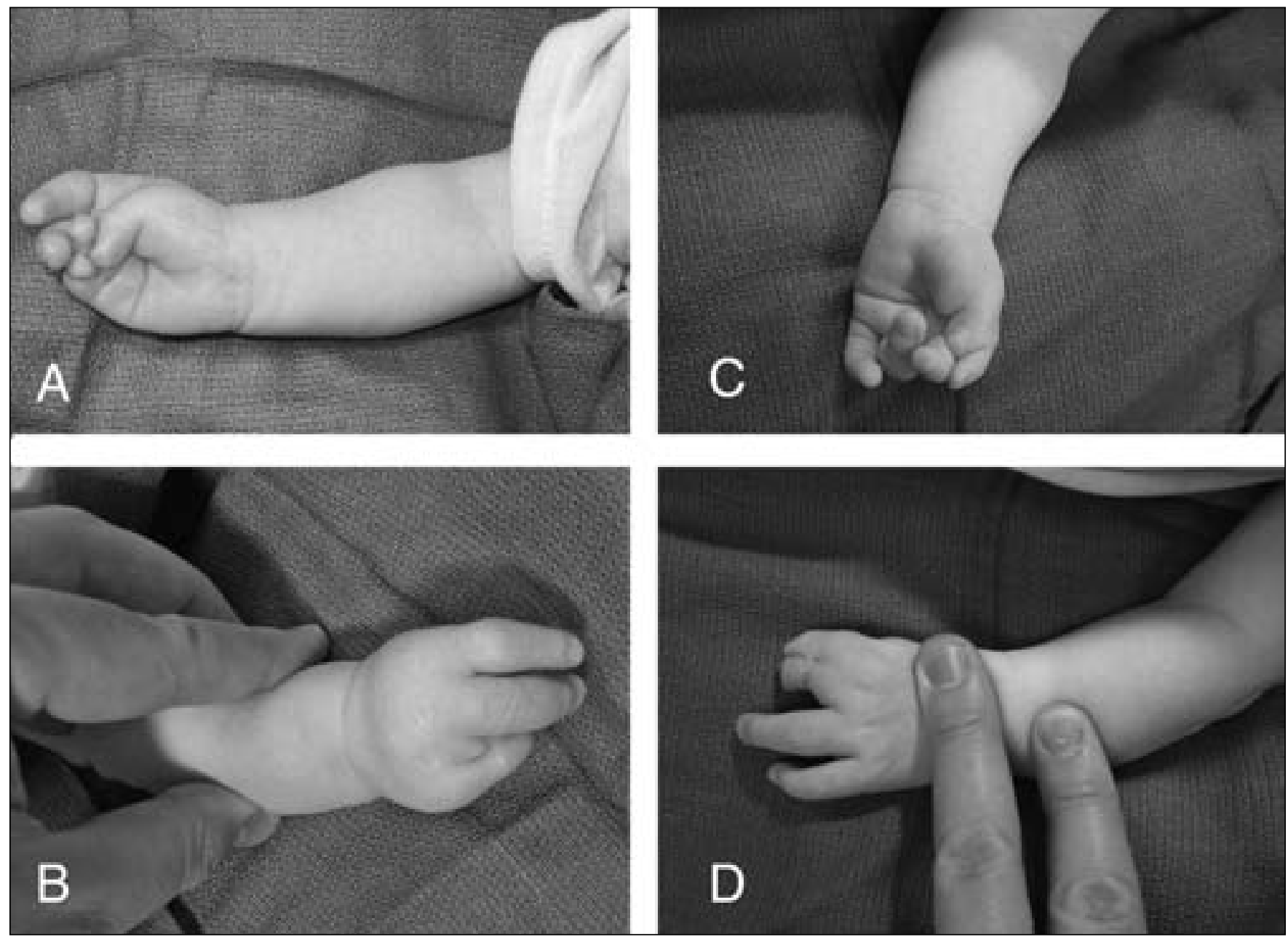

Figure 1) Appearance of the hands at four months of age. A Right hand, volar view, with acrosyndactyly involving the thumb, middle, ring and small fingers. B Right hand, dorsal view. C Left hand, volar view, with acrosyndactyly involving the thumb, index and middle fingers, and a congenital amputation of the thumb. D Left hand, dorsal view

and small fingers, and the parts were of normal size (Figure 1). At four months of age, the child underwent the first stage of the reconstructive sequence, consisting of surgical release of the thumbs of both hands with full-thickness skin grafts. At seven months of age, the child underwent release of the left second web space syndactyly, full-thickness skin grafting and deepening of the first web space with a four-flap Z-plasty. At nine months of age, surgical release of the right second web space was performed, with skin grafting and deepening of the first web space. At seven months follow-up from the last surgical procedure, the patient was meeting his growth and developmental milestones. He was using both hands with excellent coordination and grasp, and the aesthetic result was good (Figure 2). Additional procedures to further deepen the first web space, correct the left long finger constriction ring and improve thumb opposition are planned.

\section{DISCUSSION}

The pathogenesis of constriction band syndrome is unknown. The exogenous theory was proposed by Torpin (2), who studied more than 400 cases of constriction band syndrome. According to Torpin, the initiating event is rupture of the amnion without rupture of the chorion. This leads to transient oligohydramnios due to passage of amniotic fluid through the relatively permeable chorion. Contact of the fetus with 'sticky' mesoderm on the chorionic surface of the amnion would lead to entanglement of fetal parts and skin abrasions. Entanglement of the fetal parts would cause constriction rings and amputations, whereas skin abrasions would lead to disruption defects, such as omphaloceles. Swallowing of the bands would cause facial clefting (17).

Some of the clinical features of constriction band syndrome are not explained by the exogenous mechanism, such as the association with internal anomalies, such as tracheoesophageal fistulas, renal agenesis and cardiac defects. There are also many cases of constriction bands occurring in the absence of amniotic rupture. These clinical findings led Lockwood et al $(3,6)$ to search for an endogenous mechanism. Experiments involving the introduction of vasoactive substances in rats have reproduced external and internal features of amniotic band syndrome without disruption of the amnion $(3,18)$. The proposed pathogenesis would involve damage of the mesenchymal and endothelial cells of the superficial vessels of the embryo and the amnion, with disruption of epiblastic cells. This would lead to limb amputations, constriction bands and the other findings of constriction band syndrome (19). Amniotic band formation would be a late and secondary event, analogous to adhesion formation. 

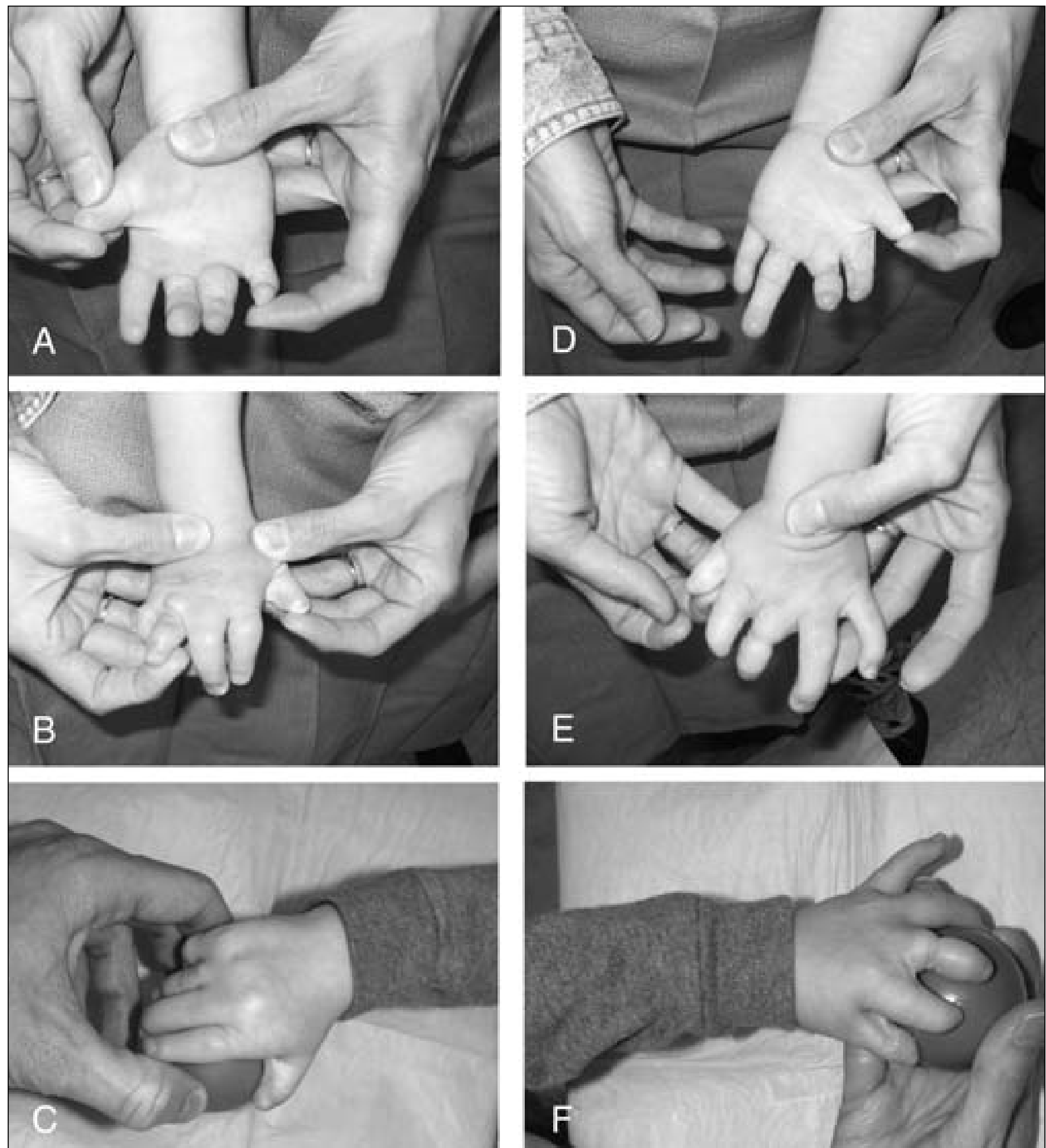

Figure 2) Appearance of the hands at 16 months of age, seven months following the third stage of the reconstructive sequence. A Right hand, volar view. B Right hand, dorsal view. C Functional grip of the right hand. D Left hand, volar view. E Left hand, dorsal view. F Functional grip of the left hand

Constriction band syndrome is a rare condition and is, therefore, difficult to study in an epidemiological fashion. However, a few large retrospective studies of risk factors have been carried out $(7,8,20,21)$. In three of four series, maternal age younger than 25 years and nulliparity were found to be significant risk factors for constriction band syndrome $(7,8,20)$. In the fourth series, a trend toward an inverse relationship between age and risk were seen, which was not statistically significant (21). The egg donor in the present case was in her early 20s and nulliparious, whereas the birth mother was 47 years of age and multiparous. If maternal youth played a role in this case, its effect was exerted through an endogenous, genetic mechanism.

There have been isolated case reports of constriction band syndrome occurring following intrauterine instrumentation, 
such as amniocentesis (11-15), chorionic villus sampling (16) or the placement of an intrauterine contraceptive device (10). No clear causative link has been established, but it is suggested that the instrumentation required in the IVF procedure may have played a role.

The debate about the pathogenesis of constriction band syndrome began with Hippocrates and continues today. Further experimental and epidemiological work will be required before either the endogenous or exogenous theories can become acknowledged as fact, and further epidemiological work is needed before we can conclude that IVF is a risk factor for constriction band syndrome. For the present, mothers to undergo invasive intrauterine procedures should probably be counselled about the potential risk of constriction band syndrome.

\section{REFERENCES}

1. Buyse ML, ed. Birth Defects Encyclopedia. Cambridge: Blackwell Scientific Publications, 1990.

2. Torpin R. Fetal Malformations Caused by Amnion Rupture During Gestation. Springfield: Charles C Thomas, 1968:1-76.

3. Kino Y. Clinical and experimental studies of the congenital constriction band syndrome, with an emphasis on its etiology. J Bone Joint Surg Am 1975;57:636-43.

4. Streeter GL. Focal deficiency in fetal tissues and their relation to intrauterine amputation. Contrib Embryol 1930;33:41-9.

5. Lockwood C, Ghidini A, Romero R. Amniotic band syndrome in monozygotic twins: Prenatal diagnosis and pathogenesis. Obstet Gynecol 1988;71:1012-6.

6. Lockwood C, Ghidini A, Romero R, Hobbins JC. Amniotic band syndrome: Reevaluation of its pathogenesis. Am J Obstet Gynecol 1989;160:1030-3.

7. Bower C, Norwood F, Knowles S, Chambers H, Haan E, Chan A. Amniotic band syndrome: A population-based study in two Australian states. Pediatr Perinat Epidemiol 1993;7:395-403.
8. Garza A, Cordero JF, Mulinare J. Epidemiology of early amnion rupture spectrum of defects. Am J Dis Child 1988;142:541-4.

9. Tanaka O, Koh T, Otani H. Amniogenic band anomalies in a fifthmonth fetus and in a newborn from maternal oophorectomy during early pregnancy. Teratology 1986;33:187-93.

10. Csecsei K, Szeifert GT, Papp Z. Amniotic bands associated with early rupture of amnion due to an intrauterine device. Zentralbl Gynakol 1987;109:738-41.

11. Kohn G. The amniotic band syndrome: A possible complication of amniocentesis. Prenat Diagn 1987;8:303-5.

12. Moessinger AC, Blanc WA, Byrne J, Andrews D, Warburton D, Bloom A. Amniotic band syndrome associated with amniocentesis. Am J Obstet Gynecol 1981;141:588-91.

13. Ashkenazy M, Borenstein R, Katz Z, Segal M. Constriction of the umbilical cord by an amniotic band after midtrimester amniocentesis. Acta Obstet Gynecol Scand 1982;61:89-91.

14. Lage JM, VanMarter LJ, Bieber FR. Questionable role of amniocentesis in the etiology of amniotic band formation. A case report. J Reprod Med 1988;33:71-3.

15. Strauss A, Hasbargen U, Paek B, Bauerfeind I, Hepp H. Intra-uterine fetal demise caused by amniotic band syndrome after standard amniocentesis. Fetal Diagn Ther 2000;15:4-7.

16. Christiaens GC, Van Baarlen J, Huber J, Leschot NJ. Fetal limb constriction: A possible complication of CVS. Prenat Diagn 1989;9:67-71.

17. Higginbottom MC, Jones KL, Hall BD, Smith DW. The amniotic band disruption complex: Timing of amniotic rupture and variable spectra of consequent defects. J Pediatr 1979;95:544-9.

18. Herva R, Karkinen-Jaaskelainen M. Amniotic adhesion malformation syndrome: Fetal and placental pathology. Teratology 1984;29:11-9.

19. Clavert JM, Clavert A, Issa WN, Buck P. Experimental approach to the pathogenesis of the anomalies of amniotic disease. J Pediatr Surg 1980;15:63-7.

20. Orioli IM, Ribeiro MG, Castilla EE. Clinical and epidemiological studies of amniotic deformity, adhesion, and mutilation (ADAM) sequence in a South American (ECLAMC) population. Am J Med Genet A 2003;118:135-45.

21. Werler MM, Louik C, Mitchell AA. Epidemiologic analysis of maternal factors and amniotic band defects. Birth Defects Res A Clin Mol Teratol 2003;67:68-72. 